\title{
A comparative analysis of retention values obtained on fused silica capillary columns from various manufacturers
}

\author{
V.G. Berezkin, A.A. Korolev, and I.V. Malyukova \\ Institute of Petrochemical Synthesis, Russian Academy of Sciences, Leninsky pr., 29, 117912 Moscow, Russia
}

\begin{abstract}
A comparative analysis of retention characteristics obtained on fused silica capillary columns available from various manufacturers is performed. The retention indexes for organic compounds of different chemical classes (octanol-1, 2,6dimethylphenol, 2,6-dimethylaniline, naphthalene, methylpelargonate) are measured on the columns. The maximum variation in retention indexes is 1,63 i.u. on the columns coated with nonpolar stationary liquid phase (polydimethylsiloxane) and 16.26 i.u. on those coated with polar that (polyethylene glycol). The average maximum variation in the retention indexes obtained on the polyethylene glycol columns is more than that on the polydimethylsiloxane columns by a factor of 5 . The established variation in columns selectivity from various manufacturers must be taken into account both in routine chromatography, in studies of physicochemical characteristics and when compiling of data bases.
\end{abstract}

Keywords. Capillary chromatography - capillary column - reproducibility of retention values - comparison of capillary columns from various manufacturers.

\section{Introduction}

Presently capillary chromatography is currently the main variant of analytical gas chromatography. A broad assortment of high performance capillary columns available commercially from numerous manufacturers favoured widespread use of capillary gas chromatography. These columns are appreciably standard. This is considered to mean possible interchangeablitily of the same columns from various manufacturers.

Taking into account analytical application of the columns and such general requirement as a reproducibility of their chromatographic characteristics it was of great interest to compare experimentally the retention values for various sorbates obtained on capillary columns coated with stationary liquid phases (SLP) of the same type available from various manufacturers. Note, some years ago the results of the experimental study for the columns available from other manufacturers were published in inaccessible Russian journal Zavodskaya laboratoriya [1]. In our opinion, the reproducibility of the capillary columns available from various manufacturers is of general interest for many chromatographers by the following reasons.

Firstly, the data on the reproducibility are necessary for general approach when compiling of databases on the retention. Secondly, the data must be taken into account when changing the column from one manufacturer for that from other manufacturer. And, thirdly, the data are necessary for general estimation of the reproducibility of chromatographic characteristics of the columns from various manufacturers.

The identity of the column properties from various manufacturers is unlikely to be rather great because the following factors can have a significant influence on the retention:

- the properties of polymer SLP used by various manufacturers;

- the preparation techniques of internal capillary surface before coating, the methods used for immobilization of SLP. There is no question that these factors should influence the sorption characteristics of the column (see, e.g. [2]);

- the nature and pressure of the carrier gas used [3].

The separate assessment of all these factors is a very difficult task. Its solution is beyond the scope of our report.

The purpose of this study was to study experimentally the variation in retention values for organic sorbates on the capillary columns of the same type coated with polar and nonpolar SLP available from various manufacturers and to evaluate the results for chromatography practice.

\section{Experimental}

A general approach included, firstly, using organic solutes of various polarity for measuring the retention values (Kovats' indexes) on the capillary columns from leading 
manufacturers from USA, Europe and Australia. Secondly, the capillary columns of close geometrical parameters (length and internal diameter) and close film thickness of SLP $(0.25 \mu \mathrm{m})$ were used. Thirdly, the capillary columns coated with both polar (polyethylene glycol) and nonpolar (polydimethylsiloxane) SLP were used. Fourthly, chromatographic measurements were performed at the same experimental conditions (oven temperature, carrier gas pressure); and, fifthly, helium used as a carrier gas which has the least influence on the retention [4].

Chromatographic measurements were made on a modified LKhM-8MD gas chromatograph equipped with a flame ionization detector (FID) (factory "Khromatograf", Moscow). Fused silica capillary columns $30 \mathrm{~m}$ length $x$ $0.25 \mathrm{~mm}$ i.d., $30 \mathrm{~m}$ length $\times 0.22 \mathrm{~mm}$ i.d. (SGE, Australia) were used. Inlet pressure of helium as carrier gas was $1,2 \mathrm{~atm}$. Split ration was 1:150. The oven and detector temperature was $100{ }^{\circ} \mathrm{C}$ (for columns with polydimethylsiloxane) and $150{ }^{\circ} \mathrm{C}$ (for columns with polyethylene glycol). The injector temperature was $250{ }^{\circ} \mathrm{C}$. The sensitivity of FID was $1 \times 10^{-11}$ Ampers for scale (Afs). The sorbate retention time was measured using a modified I-02 integrator (factory "Mikroprovod", Kishinev) with a resolution of 0,1 s.

Before measurements the columns were conditioned in the flow of helium during 2 hours at $200{ }^{\circ} \mathrm{C}$ (columns coated with polyethylene glycol) and at $250{ }^{\circ} \mathrm{C}$ (columns coated with polydimentylsiloxane).

The sample was introduced with a $1-\mu 1$ microsyringe. Methane $(0.5 \mu \mathrm{l})$ and a mixture of test compounds $(0.05 \mu \mathrm{l})$ were introduced simultaneously into the column. The mixture of test compounds contained octanol-1, 2,6dimethylphenol, 2,6-dimethylaniline, naphthalene, methylpelargonate ( $2 \%$ of each component in n-hexane). For the columns coated with polydimethylsiloxane $\sim 1 \%$ of n-alkanes $\mathrm{C}_{10}-\mathrm{C}_{13}$ was added to the mixture, for the columns coated with polyethylene glycol $-\mathrm{n}$-alcohols $\mathrm{C}_{9}-\mathrm{C}_{12}$ and ndecanol-2.

Note that homologous series of n-alkanes were used as standards on the nonpolar phase and homologous series of n-alcohols were used for polar that [2]. The above mentioned test compounds present the simplified Grob test mixture [5]. It contains compounds of various polarity. This allows establishment of specific interactions of the compounds not only with used stationary liquid phases but with capillary wall as well. The wall can contain adsorption (e.g., acidic) centres. Moreover the used mixture contains available compounds.

\section{Discussion}

Kovats' indexes obtained on open capillary columns coated with polydimethylsiloxane with thickness of SLP of $0,25 \mu \mathrm{m}$ are presented in Table I. The columns were from 4 various manufacturers:

1. Supelco (Supelco Park, Bellefonte, PA 16823, USA) SPB-1 and Supelcowax 10 columns;

2. J\&W Scientific (91 Blue Ravine Road, Folsom, CA 95630-4714, USA) - DB-1 and DB-Wax columns;

3. Phenomenex (2320 W, 205th St. Torrance, CA 905011456, USA) - Zebron ZB-1 and ZB-Wax columns;

4. SGE (111 Arden Street, North Melbourne, Australia, 3051) - BP-1 and BP-20 columns.

To compare the columns from various manufacturers the values of standard deviation(s) from average value of the retention index, maximum variation in retention indexes $\left(\Delta \mathrm{I}_{\max }\right)$, and average values for all sorbates $\left(\mathrm{S}_{\mathrm{av}} \Delta \mathrm{I}_{\max \text { av. }}\right)$.

As seen from the Table I, for the columns with polydimethylsiloxane the mean standard deviation $s$ is 0,50 i.u., average maximum variation in retention index $\left(\Delta \mathrm{I}_{\max \text { av. }}\right)$ is 1,32 i.u. with maximum variation of 1,63 i.u.

The observed variation in retention indexes for the columns from various manufacturers are pronounced, especially taking into account the fact that presently measurement accuracy of retention indexes is not worse than 0,05 i.u. (see, for example, [6]). Thus, maximum variation in retention indexes is greater than measurement accuracy by a factor of 30 .

Kovats' indexes for organic sorbates on the columns with polyethylene glycol from the same manufacturers are listed in Table II. As follows for the columns with polyethylene glycol the mean standard deviation is 2,2 i.u., average maximum variation in retention index $\left(\Delta \mathrm{I}_{\max \text { av. }}\right)$ is 6,06 i.u. with

Table I. Kovats indexes $\left(I_{i}\right)$ for organic compounds on open capillary columns coated with polydimethylsiloxane from various manufactures, standard - n-akanes homologous series (see, Experimental for experimental conditions).

\begin{tabular}{|c|c|c|c|c|c|c|c|}
\hline & \multirow[t]{2}{*}{ Sorbate } & \multicolumn{4}{|c|}{ Manufacture } & \multirow[t]{2}{*}{$S$} & \multirow[t]{2}{*}{$\Delta I_{\max }$} \\
\hline & & Supelco & $J \& W$ Scientific & Zebron & $S G E$ & & \\
\hline 1 & Octanol-1 & $1051.43 \pm 0.15$ & $1051.79 \pm 0.06$ & $1052.54 \pm 0.03$ & $1052.35 \pm 0.14$ & 0.44 & 1.11 \\
\hline 2 & 2,6-Dimethylphenol & $1080.49 \pm 0.03$ & $1081.07 \pm 0.05$ & $1081.55 \pm 0.09$ & $1082.02 \pm 0.74$ & 0.57 & 1.53 \\
\hline 3 & 2,6-Dimethylaniline & $1135.52 \pm 0.07$ & $1136.26 \pm 0.06$ & $1137.15 \pm 0.06$ & $1136.34 \pm 0.26$ & 0.58 & 1.63 \\
\hline 4 & Naphthalene & $1159.62 \pm 0.06$ & $1160.84 \pm 0.04$ & $1161.23 \pm 0.03$ & $1160.72 \pm 0.06$ & 0.60 & 1.61 \\
\hline \multirow[t]{2}{*}{5} & Methylpelargonate & $1205.64 \pm 0.04$ & $1205.74 \pm 0.05$ & $1206.38 \pm 0.09$ & $1206.28 \pm 0.06$ & 0.32 & 0.74 \\
\hline & & & & & Average & 0.50 & 1.32 \\
\hline
\end{tabular}




\section{Original articles}

Table II. Kovats indexes $\left(\mathrm{I}_{\mathrm{i}}\right)$ for organic compounds on open capillary columns coated with polyethylene glycol from various manufactures, standard - n-alcohols homologous series (see, Experimental for experimental conditions).

\begin{tabular}{|c|c|c|c|c|c|c|c|}
\hline \multicolumn{2}{|r|}{ Sorbate } & \multicolumn{4}{|c|}{ Manufacture } & \multirow[t]{2}{*}{$S$} & \multirow[t]{2}{*}{$\Delta I_{\max }$} \\
\hline & & Supelco & $J \& W$ Scientific & Zebron & $S G E$ & & \\
\hline 1 & Methylpelargonate & $832.21 \pm 0.08$ & $833.72 \pm 0.05$ & $836.23 \pm 0.03$ & $834.74 \pm 0.13$ & 1.47 & 4.02 \\
\hline 2 & Decanol-2 & $870.30 \pm 0.08$ & $870.81 \pm 0.03$ & $870.74 \pm 0.04$ & $870.77 \pm 0.08$ & 0.21 & 0.51 \\
\hline 3 & Naphthalene & $1021.73 \pm 0.25$ & $1014.25 \pm 0.12$ & $1018.58 \pm 0.07$ & $1017.26 \pm 0.13$ & 2.69 & 7.48 \\
\hline 4 & 2,6-Dimethylaniline & $1104.07 \pm 0.10$ & $1104.46 \pm 0.06$ & $1105.85 \pm 0.07$ & $1103.78 \pm 0.01$ & 0.79 & 2.07 \\
\hline 5 & 2,6-Dimethylphenol & $154.69 \pm 0.10$ & $1147.88 \pm 0.07$ & $1164.14 \pm 0.12$ & $1157.64 \pm 0.14$ & 5.84 & 16.26 \\
\hline & & & & & Average & 2.20 & 6.06 \\
\hline
\end{tabular}

Table III. Characteristics of linear equation (1) when using capillary columns coated with nonpolar (polydimethylsiloxane) and polar (polyethylene glycol) SLP (see, Experimental for experimental conditions).

\begin{tabular}{|c|c|c|c|c|c|c|c|c|}
\hline \multirow[t]{2}{*}{ Manufacture } & \multicolumn{4}{|c|}{ Polydimethylsiloxane columns } & \multicolumn{4}{|c|}{ Polyethylene glycol columns } \\
\hline & $A$ & $B$ & $R$ & $S D$ & $A$ & $B$ & $R$ & $S D$ \\
\hline J\&W Scientific & 0.514 & 1.000 & 0.999 & 0.487 & 16.71 & 0.981 & 0.999 & 3.97 \\
\hline Phenomenex & 1.657 & 0.999 & 0.999 & 0.442 & -8.554 & 1.011 & 0.999 & 5.08 \\
\hline SGE & 5.506 & 0.996 & 0.999 & 0.271 & 2.133 & 0.998 & 0.999 & 3.40 \\
\hline
\end{tabular}

maximum variation of 16,26 i.u. As seen, the variation in retention indexes for the columns with polyethylene glycol is greater than that for the columns with polydimethylsiloxane by a factor of $4-5$.

Such great increase in intermanufacturer difference when changing non-polar phase for polar that is due to the fact that production of the columns with polar phases is characterized by worse reproducibility. It seems likely, that it is true up to the present.

Note, in the present study the variation in retention indexes is practically the same for analogous columns we pointed in the previous publication [1]. This justifies the stability of capillary columns characteristics produced for several years.

The results obtained reveal that when changing the capillary column from one manufacture for that of the same type from the other one the separation of the complex mixture can significantly change. Thus the unwanted consequences of such change should be taken into account in practical chromatographic analysis.

It seems likely that the value of databases can be markedly increased if they are obtained on the columns from fixed manufactures (i.e. on the columns produced by appointed technology).

Also it was of practical and theoretical interest to estimate the existence of correlation between retention indexes on the same type columns from various manufacturers.

Earlier we showed theoretically and experimentally that linear dependence for retention indexes obtained in various laboratories on the capillary columns with the same SLP was valid [7]. By applying the dependence to the retention indexes for the columns from various manufactures the equation proposed earlier can be written as:

$$
\mathrm{I}_{\mathrm{i}}(\mathrm{b})=\mathrm{A}+\mathrm{B} \bullet \mathrm{I}_{\mathrm{i}}(\mathrm{a})
$$

where $I_{i}(b)$ and $I_{i}(a)$ are retention indexes for $i$ sorbate for the columns from manufactures $\mathrm{b}$ and a respectively, $\mathrm{A}$ and $\mathrm{B}$ are constants at given experimental conditions. The retention indexes for the columns from "Supelco" were arbitrary chosen as $I_{i}(a)$.

The general variation in the retention indexes on the columns coated with SLP of the same type evaluated quantitatively by correlation coefficient $\mathrm{R}$ and mean standard deviation SD [8] (see Table III). As seen, the dependence (1) is considered to be linear $(\mathrm{R}>0,999)$. The mean standard deviation for polar SLP (polyethylene glycol) is greater than that for nonpolar one (polydimethylsiloxane) by a factor of 8-12. The application of linear regression enables use of data obtained on column from manufacturer A to derive data for another manufacturer B. This is of practical and scientific interest.

Note, that equation (1) conformed well to the experimental data for nonpolar stationary liquid phase and did much worse for polar that. Most probable it can be explained by greater contribution of adsorption phenomena for polar phases.

The obtained linear dependence can be used for approximate transition from the retention data on the columns from one manufacture to those from another one, for example from $I_{i}(a)$ to $I_{i}(b)$.

In summary it may be said that the differences in retention indexes should be taken into account both in analytical 
practice of chromatography and in studies of various regularities linking the physicochemical (or analytical) characteristic of analysing compounds with their retention indexes (retention values).

\section{Acknowledgement}

The authors are grateful to Supelco, J\&W Scientific, Phenomenex and SGE for providing the capillary columns for the given research.

\section{References}

1. Berezkin, V.G.; Korolev, A.A. Zavodskaya laboratoriya 1996, 62, 11 (in Russian).

2. Berezkin, V.G. Gas-Liquid-Solid Chromatography; M.Dekker: New York, 1991.

3. Berezkin, V.G.; Korolev, A.A.; Malyukova, I.V. Analusis 1997, 25, 299.

4. Berezkin, V.G.; Korolev, A.A.; Malyukova I.V. J. Microcolumn Sep. 1996, 8, 389.

5. Grob, K.J.; Grob, G.; Grob. K. J. Chromatogr. 1978, 156, 1.

6. Matisova, E.; Kuran, P. Chromatographia 1990, 30, 328.

7. Berezkin, V.G. Chem. Anal. (Warsaw) 1993, 38, 649.

8. Gordon, A.J.; Ford, R.A. A handbook of practical data, techniques and references; Wiley: New-York-Sidney-Toronto, 1972. 